\title{
Correspondence
}

Because of heavy pressure on our space, correspondents are asked to keep their letters short.

\section{Prevention of Carcinoma of Cervix}

SIR, - The literature ${ }^{1-6}$ provides various figures for the prevalence and annual incidence rates of cervical carcinoma-insitu and the annual incidence rate of invasive cervical squamous carcinoma. For a population at risk consisting of females over the age of 20 it seems that these are likely to be of the following order-prevalence of in-situ 1:150, annual incidence of in-situ 1,500, annual incidence of invasive $1: 3,000$. Further, it is probable that approximately half of all cervical lesions presently designated insitu progress to become invasive. ${ }^{\circ}$ May I, in the light of these provisional estimates, comment on the recent papers (June 22, pp. 1631 and 1637) which have been concerned inter alia with types and costing of programmes for regular cytological screening of well women in this country.

Type of Screening Programme-Dr. Marie P. S. Grant (June 22, p. 1637) suggests limiting the programme to postnatal and gynaecological patients. The annual birth rate in the population at risk as defined is about $1: 20$. Three thousand women produce one invasive in one year. In a group of 3,000 women there will be 150 post-natal patients in one year, the latter harbouring one in-situ which some time will become "half " an invasive. Thus post-natal screening might enable $50 \%$ of cervical cancers to be prevented. It is, however, likely to achieve much less, for the prevalence of in-situ in such women is much lower than the natural general rate applied in the foregoing calculation-post-natals are either primiparous women, therefore young and having a low prevalence rate, or multiparous, therefore previously screened and also having a low prevalence rate. The additional screening of gynaecological patients makes only a fractional difference - Lawson ${ }^{8}$ found that only $6.5 \%$ of patients with cervical cancer had ever previously attended a gynaecological clinic.

Dr. J. Elizabeth MacGregor and Sir Dugald Baird (June 22, p. 1631) suggest five-yearly screening of parous women in the age range 25-60. Again, 3,000 women in five years produce five invasives. If they are screened for the first time at the beginning of the five-year interval, 20 in-situs are discovered. How many of the latter become invasive during the subsequent five years, and, accordingly, how much cancer is prevented is not certainly known. However, Petersen ${ }^{7}$ in his followup study of 127 " untreated in-situs " found that about $20 \%$ became clinical invasive disease within five years, If his cases are regarded as comparable to those found by the screening programme, of the 20 in-situs four become invasive during the five years in question. The fifth invasive goes through its whole in-situ stage within the five-year interval and it continues to appear between second and subsequent re-screenings. Parous women in the age range 25-55 comprise about half the population at risk and to confine the programme to them probably does not greatly reduce the number of invasives prevented. Five-yearly screening of this high risk half might reduce the incidence of cervical cancer by about $75 \%$.

Costing.-The cost per smear $(2,700$ smears for $£ 1,135$ ) arrived at by Dr. MacGregor and Sir Dugald Baird agrees well with that calculated by McLaren," namely, something of the order of 10 s. In this country there are about $15,000,000$ women in the population at risk. Fiveyearly screening then at 10 s. per smear of the high-risk half costs $£ 750,000$ per annum. Any saving effected by our being relieved of the need to detect invasive disease is trifling.

The Aberdeen workers dismiss the cost of treatment of in-situs discovered by the screening programme, suggesting that money spent thus is more than offset by money saved consequent to our being relieved of the necessity to treat the same cases become invasive. This regrettably is fallacious. Money is saved only in relation to the one-third of invasive cancers at present successfully treated. For the others, cervical cancer is the patients' terminal illness-women prevented from dying of cervical cancer will still die in some other (presumably no less expensive) way. The $15,000,000$ women in the population at risk produce 10,000 in-situs each year-the suggested scheme for " $75 \%$ prevention" reveals nearly 8,750 in-situs annually. However, equivocal lesions were also picked up by cytological screening. They were probably at least as numerous as "true" insitus and many require "treatment" by cervical conization for exact identification. On the other hand, with regular screening more in-situs are detected at earlier stages in their life-histories and so more are probably treatable by conservative procedures. Even taking account of the "saving on invasives," the bill for the treatment of lesions discovered by the suggested scheme probably comes to an additional $£ 250,000$ to $£ 750,000$. Lastly, capital costs at the outset for extra laboratory space, etc., have to be met but are non-recurrent.

Based on the limited information at present available, these estimates of the efficiency and costing of a possible national screening programme are admittedly crude approximations. Notwithstanding, such a programme apparently requires an annual contribution from each of us of about sixpence. Is it not time that the Minister of Health and his colleagues invited us to make this sacrifice ?-I am, etc.,

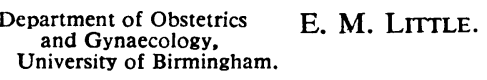

REFERENCES

1 Erickson, C. C., and Dunn, J. E., Acta Un. int Cancr., 1956, 12, 65.

Nieburgs, H. E., et al., J. Amer. med. Ass. 1957, 164, 1546.

Dunn, J. E., Amer. J. publ. Hlth, 1958, 48, 861 et al., J. nat. Cancer Inst., 1960 25, 863.

(Philad. M., and von Brit. med. J., 1962, H. K.
B. Brit. med. J., 1962, 1, 203.

(Stockh.), 1959, Wuppl, 188, E., Acta radiol awson. J, G59, Suppl. 188, 210. 1957, 64, 198 .

McLaren, H. C., The Prevention of Cervical Cancer, 1963. English Universities Press, London.

\section{Abortion and the Psychiatrist}

SIR,-Dr. Peter Darby (August 24, p. 501) bases some criticisms of my paper "Abortion and the Psychiatrist" (July 20, p. 145) on what he considers are my wrong interpretations of four out of its 22 references. He claims that Ekblad ${ }^{1}$ did not "conclude" that the psychiatrically abnormal find it more difficult than the psychiatrically normal to stand the stress implied in a legal abortion and that the greater the psychiatric indications for a legal abortion, the greater will be the risk of unfavourable psychic sequelae after the operation. He does not dispute that Ekblad said this in his monograph, "but it was in the first two sentences of the summary of a quite different chapter. ...” In Chapter XII, Ekblad describes "mental sequelae and self-reproaches on account of the abortion." In the following chapter (XIII) he explores the "connexion between the occurrence of self-reproaches for the abortion and various factors in the woman's mental constitution and environment. He divides the "psychiatrically normal" from the "psychiatrically abnormal" and shows a statistically significant difference in their reactions to the abortion. The above opinion is included in the summary and conclusions of Chapter XIII and also on p. 213 and p. 218 of Chapter XII.

That Ekblad said something different at a meeting in Stockholm in 1953, two years before his monograph appeared in 1955, I find a most unconvincing argument. I must again point out that the morbidity of Ekblad's material was generally slight (illness $16 \%$, weakness $63 \%$, foreseen weakness $14 \%$, eugenic $7 \%)$ and one can assume that in greater degrees of morbidity the sequelae would be more disturbing. This is not idle speculation, for in my own study there were eight patients with post-abortive psychoses ; four of these followed therapeutic abortion.

Siegfried's ${ }^{2}$ series consisted of " women with slight mental disturbances such as neurosis, psychopathy and dullness" as "cases with psychosis, advanced mental deficiency and epilepsy had been excluded." Yet even in this low-morbidity 
group $59 \%$ had undesirable reactions. In eight $(13 \%)$ the reaction was more severe, and Siegfried was of the opinion that "there will be a few cases in which a legal abortion will entail unfavourable mental sequelae and may injure the woman more than a completion of the pregnancy would have done. ..."

I fail to see the significance of Dr. Darby's comments on Dahlgren. ${ }^{s}$ I stated that "a pregnant woman can attempt suicide, though few are successful." That Dahlgren's five pregnant patients who attempted suicide were unmarried does not invalidate this statement or counter the evidence from the coroner's court that in approximately six years in the City of Birmingham no pregnant wcman committed suicide. He considers my conclusion that unmarried mothers are relatively immune from puerperal psychosis as due to my material being highly selected. This conclusion was based on a personal study of 213 patients with puerperal psychosis and was confirmed by a search of the records of all such patients admitted to five regional mental hospitals (two rural and three urban) over a five-year period. Where else could unmarried puerperal psychotics go? If he has data which are contrary to those which I have collected, it would have strengthened his argument if he had produced them in his letter.

I have left to the last his categorical rejection of my statement on the law and therapeutic abortion. In addition to Davidson ${ }^{4}$ I quoted from Hadfield ${ }^{5}$ that after the Rex v. Bourne (1938) case an abortion was considered lawful if performed in the interests of the mother's health, and that most gynaecologists "would not operate unless they were advised that the mother would almost certainly suffer permanent mental damage of a serious nature or would commit suicide." Unlike Dr. Darby, I do not claim to be an authority on the law of England, but I do know that the Bourne and other cases were decided in the light of medical evidence at the time and that the Director of Public Prosecutions could still bring a charge against a doctor if he had information that abortions were being advised and done on inadequate and therefore in his opinion criminal grounds. The doctor's defence would no doubt be that the mother's health was endangered by her pregnancy. The evidence I have produced and data published by others would now make such a defence very difficult.

Furthermore, a doctor who on psychiatric grounds advises or performs an abortion which is followed by undesirable mental or even physical sequelae could be sued in a civil case for negligence and he would have to satisfy the court why he recommended a procedure which does not avert suicide or psychosis but which can cause a severe psychosis. A form of consent to such an operation should read: "I hereby consent to an abortion, recom- mended by Dr. $\mathrm{X}$ and to be carried out by Mr. Y. I realize that this abortion cannot prevent any undesirable psychiatric sequelae and that it may in fact cause such, but that it is being done to relieve me of a temporary embarrassment." This might give some protection to the doctor in a civil case, but he would be very unwise to produce it in a criminal one.

I repeat that on present evidence there are no psychiatric grounds for abortion, and a doctor who advises it now runs the risk of a civil if not a criminal action, but, even more important, it is bad medical practice.-I am, etc.,

Queen Elizabeth Hospital,
Birmingham 15.

REFERENCES

${ }^{1}$ Ekblad, M., Acta psychiat. scand., 1955, Suppl. No. 99 .

S. Schweiz. Arch. Neurol. Psychiat. $1951,67,365$.

Go Sucide and Attempted Suicide, 1945. Universitats Bokhandel, Lund. Suicide, 1945. Medical Ethics Students and Practitioners, 1957. Lloyd-Luke. London.

s Hadfield, S. J., Law and Ethics for Doctors, 1958. Eyre and Spottiswoode, London.

SIR,-I agree with Dr. Myre Sim (July 20 , p. 145) that there are no psychiatric grounds for the termination of pregnancy. It is, as he states, a statutory felony to procure abortion but the law regarding therapeutic abortion is clearer than he believes. In Rex v. Bourne (1938) Mr. Justice McNaghten explained that therapeutic abortion may be done only for the purpose of preserving the life of the woman and that a doctor might be acquitted if the jury believe that he was homestly of the opinion that continuance of pregnancy would probably make her a physical or mental wreck. Dr. Sim's research shows that continuance of pregnancy never makes any woman a mental wreck and that abortion on psychiatric grounds is never justifiable.

Psychiatrists are being exploited also in other fields. Frequently some unlucky shoplifter or sexual offender runs to his doctor, crying for help and a psychiatrist. This rapid recourse to psychiatry by transgressors is to be deprecated. General practitioners should not make themselves accessories by assisting them. It is bad for the public and worse for the profession. The N.H.S. should be too respectable an umbrella to shelter every criminal Thomas, Richard, or Harold from the just consequences of his misdeeds.

The typical offender presents himself hopefully at the psychiatric clinic by appointment, with a letter from his doctor. He announces that he has been caught shoplifting and admits that he knew what he was doing and that it was wrong to do it. $\mathrm{He}$ is neither mentally disordered nor subnormal. He was not compelled to steal, it was a voluntary act. $\mathrm{He}$ intended to take goods without paying for them. If he had not been caught, he would have continued to steal. It is certain that he would not have sought "treatment," because there was nothing to treat. In mitigation, he mentions his previous good reputation, as if that should excuse everything. One can only remind him that everybody has a good character before he has been found out, and that if a bishop were to be caught shoplifting, even the episcopal character would be unmerited. Thus frequently hours of N.H.S. time are wasted, without benefit to anyone.

We have travelled a long way since thieves were scourged and handed over to their victims for vengeance or hurled from the Tarpeian rock. It is going too far, however, to nurse them in hospital at public expense, as if they were sick.I am, etc.,

St. Crispin Hospital.

Duston, Northampton.

J. J. H. LOWE.

SIR,-Dr. Myre Sim's article (July 20, p. 145) will certainly be helpful if it stimulates thought on this very controversial topic; but his "conclusion" that "there are no psychiatric grounds for termination of pregnancy" is surprising -unless of course he intends it merely to provoke correspondence.

I wonder if he has confused two questions, the general (Do psychiatric grounds. ever exist for termination ?) and the particular (Do they exist in a given case ?). It is of course the latter that many psychiatrists are asked to answer in their clinical practice. Dr. Sim is entitled to say that none of the cases he quotes warranted termination; but it is hard to see how he can logically extend this opinion to say that no other cases might do so-especially as his paper refers only to a small group of psychiatric conditions.

In any case his views have no authority to answer the general question, "Do psychiatric grounds ever exist?" for this is a legal matter. It is held by the consensus of legal opinion-even if a somewhat clearer statute would be an advantage-that psychiatric grounds do exist. Dr. Sim may wish to alter the law-as do others, in different ways-but unless and until this is done we, as psychiatrists, can only give our opinion, in good faith, as to whether an individual case has legal justification or not.

In this, surely, we must be guided by our assessment of the way the patient will react mentally to the pregnancy, if it continues ; and I, for one, fail to see how "socio-economic" factors can be ignored in making this assessment, as Dr. Sim suggests they should. I do, however, agree that psychiatrists could avoid recommending some cases for termination if they could provide more psychotherapy during their pregnancy; but this is often not possible in the present shortage of psychiatrists. I also agree that there are some cases in which termination may do more psychiatric harm than good. but this is no reason for not recommending it to others.

The decision is indeed often a harrowing one, and I can well sympathize with psychiatrists or gynaecologists involved in it ; but if they seek refuge in sweeping generalizations based on religious or 